Article

\title{
Quick Aboveground Carbon Stock Estimation of Densely Planted Shrubs by Using Point Cloud Derived from Unmanned Aerial Vehicle
}

\author{
Xueyan Zhang ${ }^{1,2}$ \\ 1 Institute of Geographical Science and Natural Resources Research, Chinese Academy of Sciences, \\ Beijing 100101, China; xyzhang@igsnrr.ac.cn; Tel.: +86-010-6488-8673 \\ 2 Center for Chinese Agricultural Policy, Chinese Academy of Sciences, Beijing 100101, China
}

Received: 9 October 2019; Accepted: 4 December 2019; Published: 5 December 2019

\begin{abstract}
Carbon sink trading is an important aspect of carbon trading in China, and can have important significance in offsetting carbon emissions and improving ecological compensation. The use of unmanned aerial vehicles (UAVs) offers new opportunities for shrub carbon sink and accounts as a substitute for time-consuming and expensive plot investigations to estimate the carbon sink by using the aboveground carbon stock monitored by UAV. However, the UAV-based estimation of the aboveground carbon stock of densely planted shrubs still faces certain challenges. The specific objectives of this research are as follows: (1) to test the statistical relationship between the aboveground carbon stock and volume of a densely planted shrub belt, and (2) to develop a model to estimate aboveground carbon stock by monitoring the volume of the densely planted shrub belt using a UAV. The study showed that (i) the aboveground carbon stock would increase with the increase in the volume of the shrub belt, (ii) an estimation model of the aboveground carbon stock of the densely planted shrub belt was developed $\left(R^{2}=0.89, P<0.01\right)$, and (iii) the validation assessment to estimate aboveground carbon stock by using the UAV-based estimation model produced a coefficient of determination of $R^{2}=0.74$ and an overall root mean square error of $18.79 \mathrm{~kg} \mathrm{CO}_{2 \mathrm{e}}$. Good prediction ability of the model was determined using leave-one-out cross-validation (LOOCV). This output information is valuable for the design of operations in the framework of precise carbon-sink accounting of shrubs. In addition, a method using an UAV was developed and validated for the quick estimation of aboveground carbon stock for densely planted shrubs, thereby providing a potential alternative to time-consuming and expensive plot investigations of aboveground carbon-stock accounting, which is necessary for shrub projects in the carbon trading market in China.
\end{abstract}

Keywords: unmanned aerial vehicle; estimation model; carbon sink; aboveground carbon stock; carbon trade; densely planted shrub; China

\section{Introduction}

To maintain global warming below $1.5^{\circ} \mathrm{C}$ to avoid dangerous climate change, $\mathrm{CO}_{2}$ must be removed from the atmosphere and emissions must be reduced [1]. China is the largest emitter of greenhouse gases and has been determined to reach its peak emissions by 2030, according to the Nationally Determined Contribution under the Paris Agreement [2]. To achieve these goals efficiently, carbon trade plays a critical role in inspiring mitigation actions. More than 20 carbon-emission-trading systems (ETSs) are in operation by governments worldwide such as the European Union (EU), United States, Canada, South Korea, and New Zealand. Jurisdictions making up 37\% of the global GDP are using emissions trading [3]. Since June 2013, seven Chinese ETS pilot projects as well as the Fujian regional ETS have entered operation for the national ETS. As of July 5, 2017, there were 96 carbon 
sink-related Chinese Certified Emission Reduction projects, and the accumulated trading volume of the spot market in all pilots reached 5258 tons $\mathrm{CO}_{2}$ equivalent $\left(\mathrm{tCO}_{2} \mathrm{e}\right)$ [4]. The Intergovernmental Panel on Climate Change (IPCC) has proposed that increasing the total area of the world's forests could sequester nearly $25 \%$ of $\mathrm{CO}_{2}$ emissions [5]. Therefore, carbon sink trading is an important part of the carbon trade in China, and can have important significance in offsetting carbon emissions.

China is seriously affected by desertification [6]. To prevent desertification, the Sand Source Control Project (SSCP) conducted by the Chinese government has completed about 8.86 million ha of afforestation in 138 counties in Inner Mongolia, Shanxi, Hebei, Beijing, and Tianjin in the past 20 years. By considering tolerance for extreme environments, shrubs, which are a dominant species in desert areas, have been widely favored and selected in the project. Shrub biomass is a net sink that accounts for about $30 \%$ of the forest sink in China [7,8]. Among the shrub species, temperate semi-shrubs and dwarf semi-shrubs have the highest carbon-storage capacities [9]. One idea is to incorporate shrubs into carbon trading to obtain ecological compensation from marketing mechanisms. However, only a few shrub-based carbon-trading projects have been implemented. Researchers studying carbon estimation have mainly focused on tree species, but not on carbon stock estimates for shrub species; this is probably because individual shrubs are small and less dominant in carbon sequestration [10]. Another major obstacle for shrub carbon trading is the time-consuming and expensive nature of plot investigations for carbon-sink accounting. The IPCC recommends ground-based surveys and allometric equations for carbon-stock accounting [11]. The limitation of ground-based surveys is that at least one sample plot is required per 50 ha and must be investigated extensively based on individual field measurements [12]. How to reduce the monitoring cost is an important problem for shrub-based carbon sink projects with a small carbon stock density and huge project area.

The use of unmanned aerial vehicles (UAVs) offers new opportunities for shrub-based carbon sink accounting through the estimation of carbon stock using aboveground carbon stock monitored by UAVs [13]. Actually, most of shrub was planted by seeds in the SSCP. The aboveground carbon stock is theoretically equal to the aboveground carbon sink because the baseline of carbon sink accounting is close to zero. An UAV can acquire real-time high-resolution images as well as offset the fixed acquisition cycle of optical-sensor satellite remote sensing and sensitivity to weather conditions (e.g., cloudiness) [14]. There are two remote sensing techniques that are suitable for application on a UAV platform: airborne laser scanning (ALS) and structure from motion (SfM). The SfM photogrammetric technique underperforms in terms of accuracy, whereas ALS can provide more accurate estimates of the vertical structure of plants [15]. However, the SfM is more accessible than ALS, which is too expensive for shrub owners in developing countries [16]. Therefore, the use of UAVs with the SfM technique allows for the detection of surface data at acceptable spatial and temporal resolutions, and is a more cost-effective solution [13].

Caragana intermedia (C. intermedia) is a perennial leguminous shrub that has strong drought tolerance and wind-proof and sand-fixation properties [17]. It is widely distributed in the desert steppe area of the Mongolian Plateau [18]. Conventional methods measure the height and crown of single C. intermedia plants and calculate the carbon stock through specific allometric equations. However, in the SSCP, C. intermedia were densely planted in strips to achieve sand fixation. In addition, the UAV faced serious challenges to calculate the aboveground carbon stock of densely planted and banded shrubs in desertification-prevention projects. The specific objectives of this research are as follows: (1) to test the statistical relationship between aboveground carbon stock and the volume of the densely planted shrub belt, and (2) to develop an estimation model of aboveground carbon stock by monitoring the volume of the densely planted shrub belt using an UAV. This output information is valuable for the design of operations in the framework of precision carbon-sink accounting of shrubs. A quick aboveground carbon-stock-estimation method using a UAV was developed for densely planted shrubs to promote the development of shrub-based carbon trading projects. 


\section{Data and Methods}

\subsection{Study Area}

The study area is located in the Chahar Right Back Banner $\left(41^{\circ} 10^{\prime} 13.133^{\prime \prime} \mathrm{N}-41^{\circ} 9^{\prime} 8.492^{\prime \prime} \mathrm{N}\right.$, $112^{\circ} 42^{\prime} 13.585^{\prime \prime} \mathrm{E}-113^{\circ} 9^{\prime} 56.475^{\prime \prime} \mathrm{E}$ ) in the central area of Inner Mongolia, China (Figure 1). Within an overall temperate continental climate, the region is characterized by an arid and semiarid climate. The average annual temperature is $6.58{ }^{\circ} \mathrm{C}$, while the average annual precipitation is $300 \mathrm{~mm}$ with up to $75 \%$ of annual rainfall occurring in summer [19]. The average annual evaporation is $2448 \mathrm{~mm}$ and the relative humidity is 55\%. The average annual wind speed is approximately $2.7-3.1 \mathrm{~m} / \mathrm{s}$, and the maximum wind speed can reach $17.0 \mathrm{~m} / \mathrm{s}$. The frost-free period is 130-140 days [20].

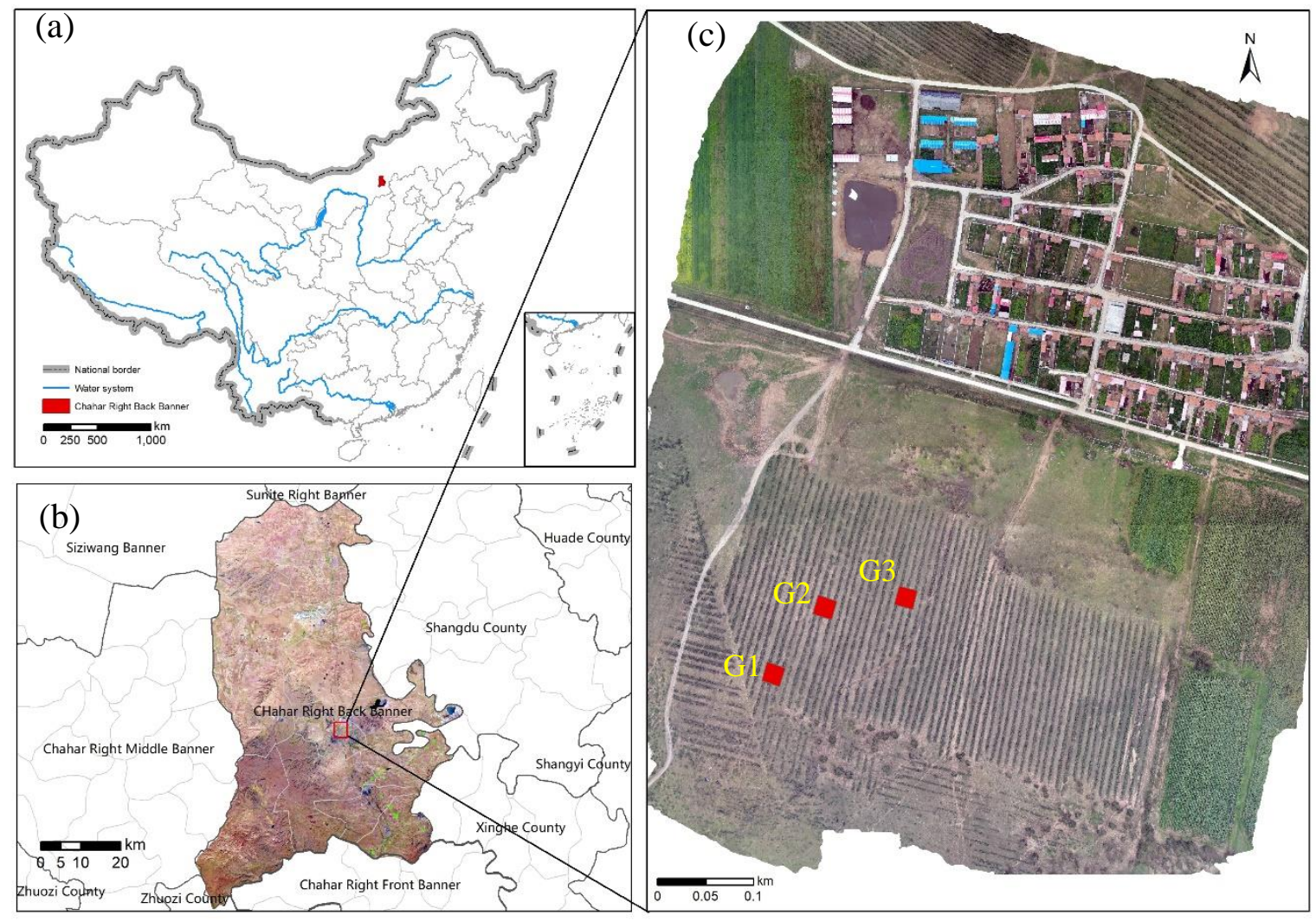

Figure 1. (a) Overview of the Chahar Right Back Banner (CRBB) located in Central Inner Mongolia, China; (b) study area in the CRBB; and (c) field plots (red squares G1, G2, and G3) in an orthophoto of the study area.

Considering the precipitation and temperature gradient, the area is dominated by grasslands and typical steppes [21,22]. The study area predominantly contains herbaceous vegetation with a vegetation cover of $25 \%-100 \%$, and is characterized by Stipa krylovii, Stipa grandis, Carex duriuscula, Leymus chinensis, and Artemisia frigida [23]. The shrub species in this area includes C. intermedia, Filii auream rursus phasianae, and Lycium. In the periphery of the study area, approximately 20,000 ha of C. intermedia were artificially planted for desertification preservation (Figure 1).

\subsection{Aboveground Carbon-Stock Accounting of the Densely Planted Shrub Belt}

(1) Sampling Scheme Design and Plant Sampling

Field data were collected on August 16, 2018 for three plots (G1, G2, and G3) of $20 \mathrm{~m} \times 20 \mathrm{~m}$ stretching across three densely planted shrub belts. The plots consisted of nine distributed belts (B1-9; Figure 2). The square border was outlined and different belts were distinguished using a red line. 
The field survey recorded the number of shrubs in each belt along with the height and crown width of each shrub. The crown width was measured at the north-south and east-west diameter of the canopy.

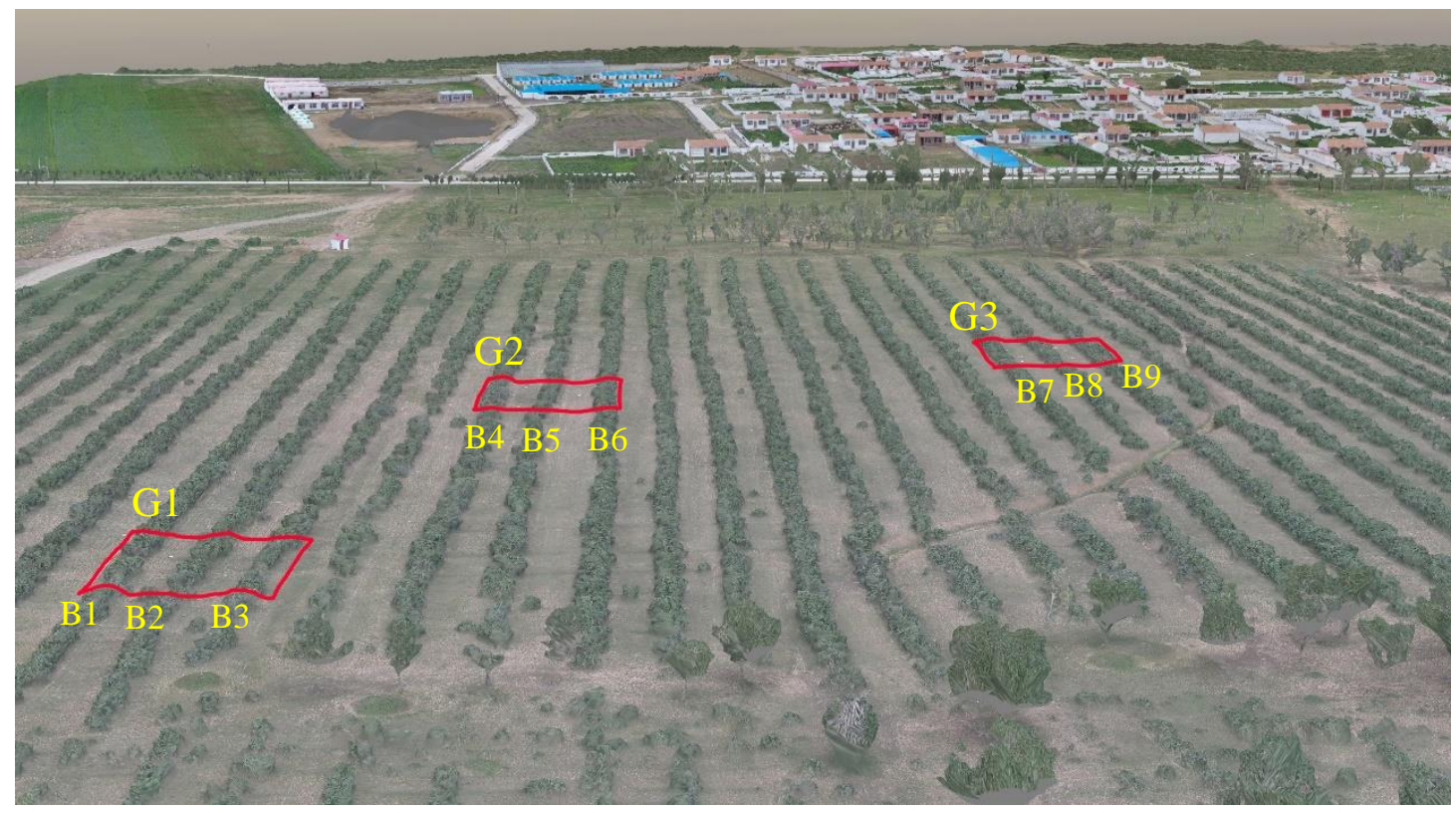

Figure 2. Distribution of plots and belts. Three C. intermedia plots were uniformly distributed from left to right, namely G1, G2, and G3, respectively. Similarly, each plot had three belts from left to right, namely B1, B2, B3, B4, B5, B6, B7, B8, and B9, respectively.

\section{(2) Aboveground Carbon-Stock Accounting Using an Allometric Equation}

Aboveground carbon stock accounting is based on plant biomass. In terms of the estimation of shrub biomass, previous studies have proposed an allometric equation based on field measurements. Different input parameters are required for various local allometric equations [24,25] including plant height, crown width, and number of branches. Some allometric equations require aboveground and underground biomass parameters, and the total biomass is the sum of the aboveground and underground parts [26,27]. The allometric equation of C. intermedia adopted in this study was constructed by Dang et al. [25]; it estimates the aboveground biomass by using the plant height and crown width measured in a field survey. The model was constructed based on the two morphological factors of plant height and crown width as the independent variables and shrub biomass as the dependent variable, as follows:

$$
W=1.245(C \times H)^{0.826}
$$

where $W$ is the aboveground biomass $(\mathrm{kg}) ; C$ is the crown width (m); and $H$ is the plant height (m). Variables $C$ and $H$ were obtained from field measurements.

The aboveground carbon stock was calculated using biomass and carbon content [27], as follows:

$$
C_{\text {stock }}=W \times C_{\text {content }} \times \frac{44}{12}
$$

where $C_{\text {stock }}$ is the aboveground carbon stock of the shrub $(\mathrm{kg}) ; W$ is the biomass $(\mathrm{kg}) ; C_{\text {content }}$ is the carbon content (0.5) [27]; and $\frac{44}{12}$ is the ratio between $\mathrm{CO}_{2}$ and carbon. 


\subsection{Shrub Belt Volume Estimation by Using UAV Data}

(1) Data Acquisition

To estimate the shrub-belt-volume, a DJI Phantom 4 Pro UAV was used, which is a quadcopter with four electric motors and equipped with a CMOS (Complementary Metal-Oxide Semiconductor) camera (ZENMUSE X3) with a focal length of $35 \mathrm{~mm}$ and effective pixel in one-inch CMOS of 20 million (Figure 3). The maximum speed and flight time of the UAV were $22 \mathrm{~m} / \mathrm{s}$ and $12-18 \mathrm{~min}$, respectively. The UAV data were acquired on 16 August, 2018, and the flight schedule was planned on a dry, nonwind day to avoid distortions caused by UAV camera undulations [28]. The flight longitude ranged from $113^{\circ} 15^{\prime} 14.218^{\prime \prime} \mathrm{E}$ to $113^{\circ} 15^{\prime} 46.286^{\prime \prime} \mathrm{E}$ and the flight latitude ranged from $41^{\circ} 26^{\prime} 15.347^{\prime \prime} \mathrm{N}$ to $41^{\circ} 26^{\prime} 44.472 \prime \mathrm{N}$. The study area covered $52.72 \mathrm{ha}$, where the $C$. intermedia shrubs covered approximately 16.16 ha and accounted for $30.65 \%$ of the total flight area.

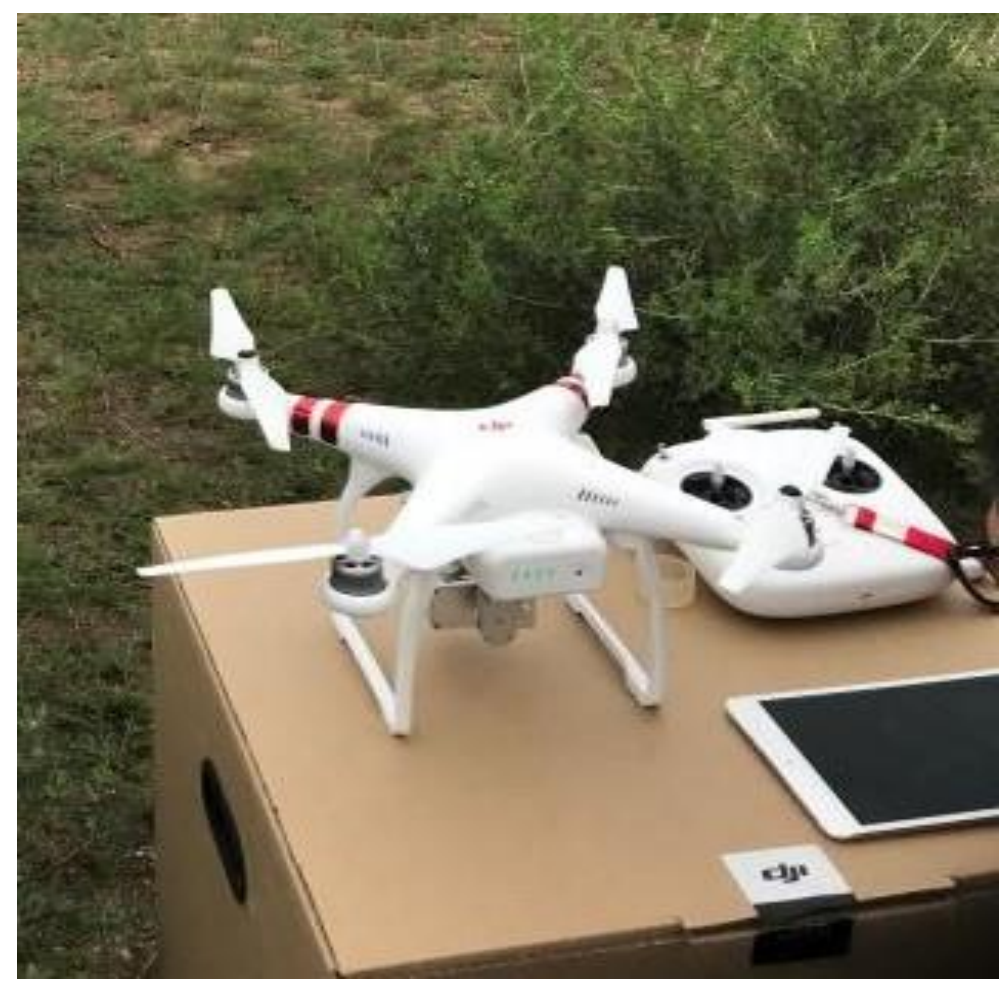

Figure 3. DJI Phantom 4 Pro UAV: a quadcopter with four electric motors, equipped with a CMOS camera (ZENMUSE X3).

Autonomous flight planning was conducted for the study area, and the flight path was designed toward the north-south direction with a speed of $11 \mathrm{~m} / \mathrm{s}$ by two flights of approximately $12 \mathrm{~min}$ each. The camera was set to an F-stop of 2.8, shutter speed of 1/2000 s, and ISO-values that were automatically adapted to the given lighting situations between 100 and 1600 ISO. The images were obtained from a height of $60 \mathrm{~m}$ with $70 \%$ side overlap, $90 \%$ forward overlap, and an optical GSD of $3 \mathrm{~cm}$. During the flight, the UAV automatically triggered the camera every $7 \mathrm{~m}$, simultaneously recording the position by using an internal GPS/GLONASS dual-mode satellite positioning system. Fifty-eight ground control points were marked and measured using real-time kinematic (RTK) equipment in field plots. The safe mode and a camera angel of $-90^{\circ}$ was preferred during the UAV image acquisition [29]. The sensor produced three 20-MP images in the red, green, and blue (RGB) wavelengths [13]. During the survey, 808 RGB images were obtained (Figure 4). 


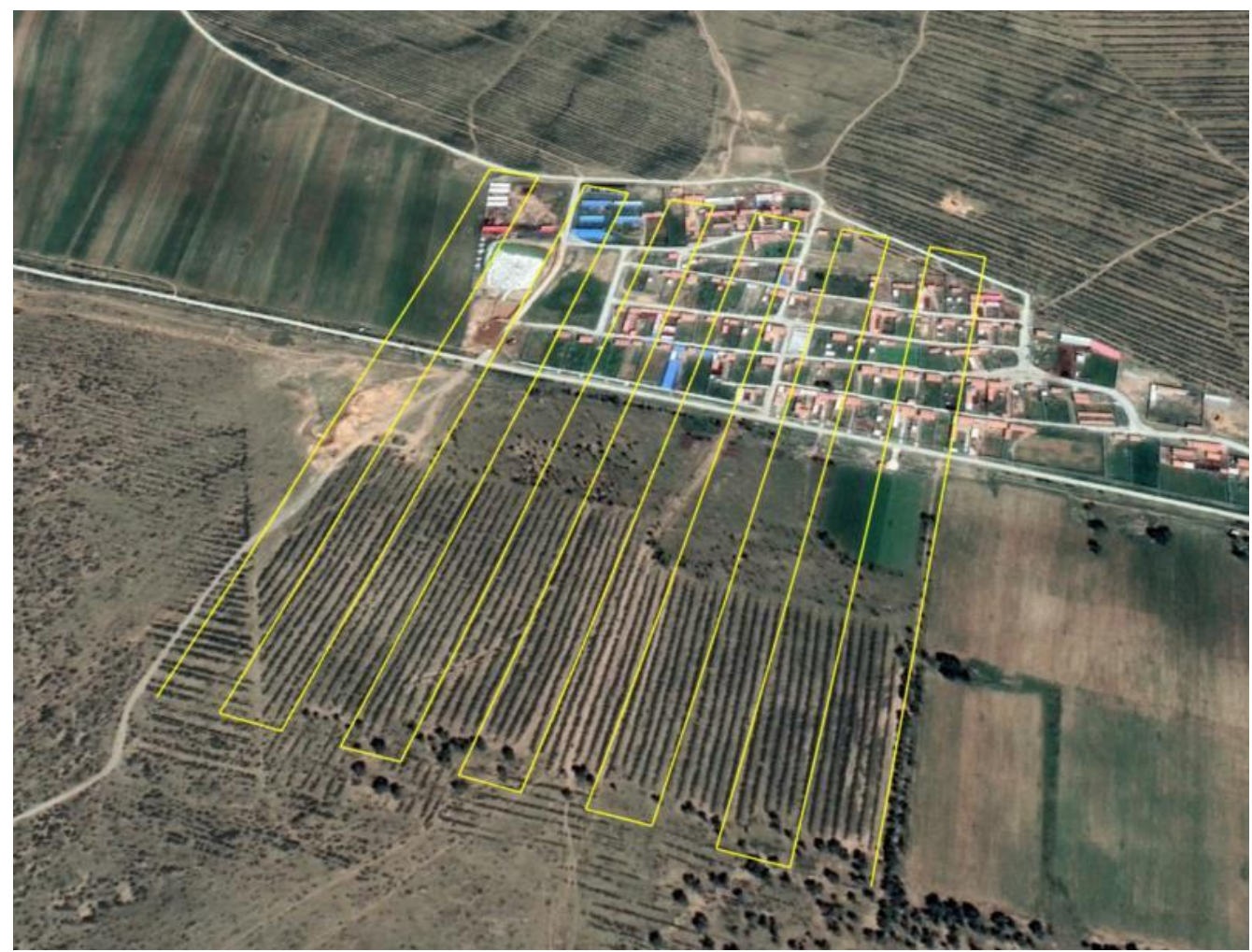

(a)

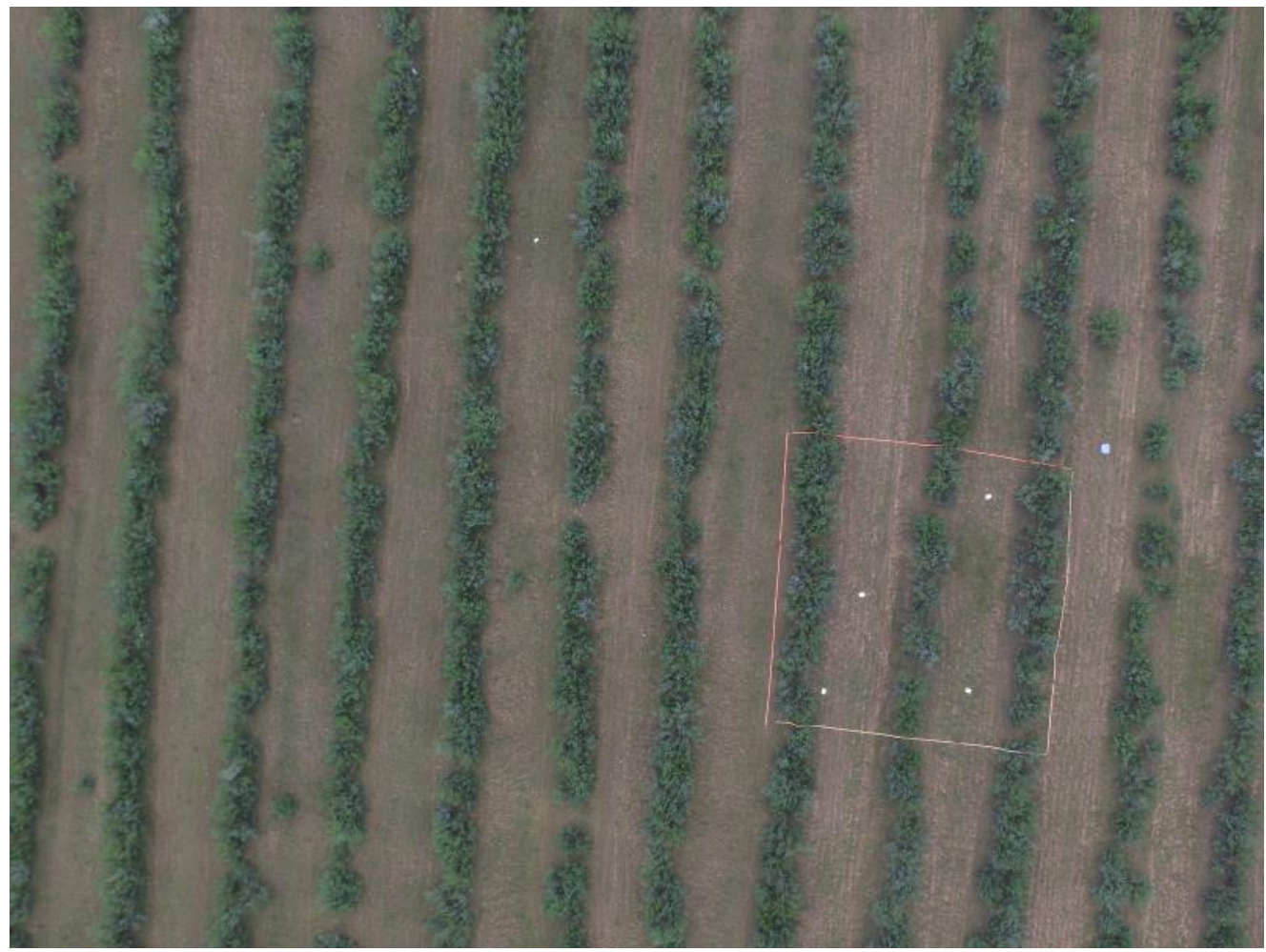

(b)

Figure 4. Flight path and ground control points. (a) Flight path in the north-south direction with a speed of $11 \mathrm{~m} / \mathrm{s}$ from a height of $60 \mathrm{~m}$; and (b) red, green, and blue wavelength images of the densely planted shrubs, shrub plot (red line), and ground control points (write points). 


\section{(2) Shrub Volume Accounting Using Photogrammetry}

The workflow of the SfM approach consists of two major steps: image alignment and geometry building. The 3D point cloud was generated using Agrisoft Photoscan Professional Edition software (Agisoft LLC, Russia) [30]. First, the camera position for each image and common points in the images were located and matched; this facilitated the fitting of calibration parameters of the camera. Second, the point cloud was built based on the estimated camera positions and images themselves [31]. A digital surface model (DSM), digital terrain model (DTM), and an orthomosaic were also generated [16]. The 3D point cloud DSM and orthophoto are shown in Figure 5a.

The volume of shrub belts can be approximated as the volume of canopy height model (CHM). In theory, a CHM can be obtained by subtracting the DTM from DSM, as recommended by González-Jaramillo et al. [32]. However, it is difficult to extract a DTM from the UAV-derived DSM because the camera cannot survey the terrain surface through the canopy [33]. First, to obtain a complete DTM, the shrub belt boundary area was extracted using manual visual interpretation in each plot (Figure $5 b$ ). Second, kriging interpolation was used to estimate the missing surface of the DTM sheltered by the shrub canopy by using ArcGIS (ESRI, US) with a pixel size of $10 \mathrm{~cm} \times 10 \mathrm{~cm}$. The control points of the kriging interpolation were selected at the 1-m buffer outside the boundary of the shrub belt (Figure $5 b$ ). To avoid boundary effects of the interpolation surface, the outer border of the interpolation surface was considered as the 5-m buffer of the shrub plot (Figure 5b). It is vital to ensure the fitting accuracy between the kriging surface and DSM. Third, the points outside the $1-\mathrm{m}$ shrub buffer in the plot were selected to verify the fitting accuracy of the kriging surface and DTM. Finally, the CHM was extracted by the kriging surface from the DSM, displaying the difference between the kriging surface and DSM. For consistency with the spatial resolution of DTM, DSM and CHM were resampled into $0.1 \mathrm{~m} \times 0.1 \mathrm{~m}$ by using ArcGIS.

Estimating the volume of shrub can be regarded as double integral to calculate the volume of the curved-surface body. Assuming that $f(x, y)$ is continuously integrable in the closed region of shrub belt, and initially assumed that $f(x, y) \geq 0$. The surface $S$ given by shrub belt $f(x, y)$ over the domain $D$. $D$ was divided into a series of smaller rectangles and the area of the $i$ th smaller rectangle was $\Delta \sigma_{i}$. Take any point in every smaller rectangle and whose height is given by $f\left(\xi_{i}, \eta_{i}\right)$. Over each of these smaller rectangles, prisms will be constructed. Therefore, the volume of each of the prisms is $f\left(\xi_{i}, \eta_{i}\right) \Delta \sigma_{i}(i=1,2, \ldots, n)$, and the total volume is $\sum_{i=1}^{n} f\left(\xi_{i}, \eta_{i}\right) \Delta \sigma_{i}$. If $\Delta \sigma_{i}$ tends to be 0 , the volume under the surface $S$ is

$$
\mathrm{V}_{\text {shrub belt }}=\iint_{\mathrm{D}} \mathrm{f}(\mathrm{x}, \mathrm{y}) \mathrm{d} \sigma
$$

In this study, the curved-surface prism of shrub was irregular, so the approximate calculation method was adopted. The CHM of the shrub belt was treated as a curved-surface body consisting of many flat-top quadrangular prisms. To calculate the volume of the CHM, each pixel of the CHM was approximated as a flat-top quadratic prism, where the volume equals the base area $(0.1 \mathrm{~m} \times 0.1 \mathrm{~m})$ multiplied by the height (canopy height). The total volume of the shrub belt is formulated as follows:

$$
V_{\text {shrub belt }}=\sum_{i=1}^{n} S_{\text {base }, i} \times H_{\text {canopy }, i}
$$

where $V_{\text {shrub belt }}$ is the volume of the shrub belt $\left(\mathrm{m}^{3}\right) ; S_{\text {base }, n}$ is the base area of the $n$th quadrangular prism $\left(\mathrm{m}^{2}\right) ; H_{\text {canopy, } n}$ is the height of the $n$th quadrangular prism $(\mathrm{m})$; and $n$ is the number of the quadrangular prisms within the shrub belt. 


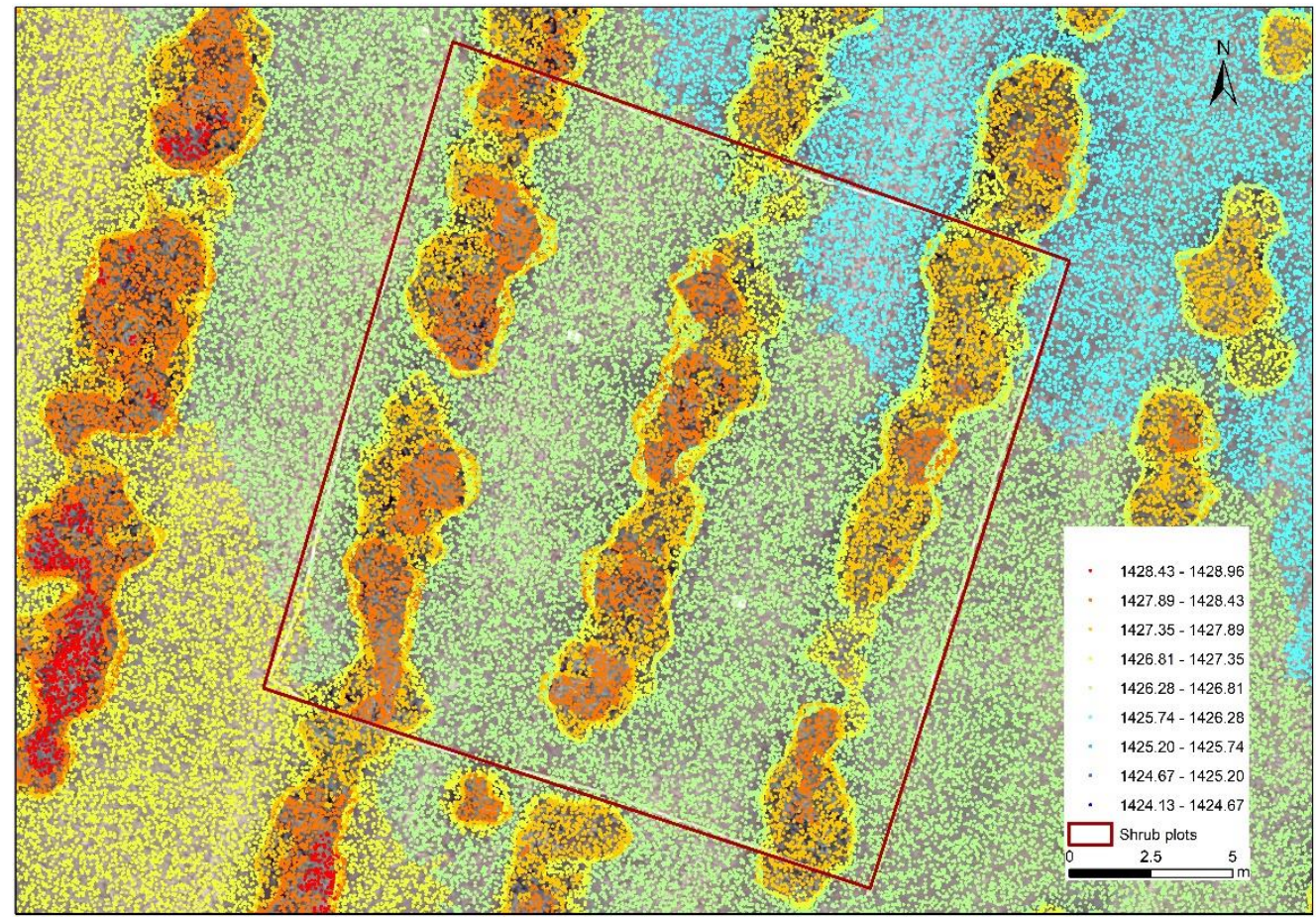

(a)

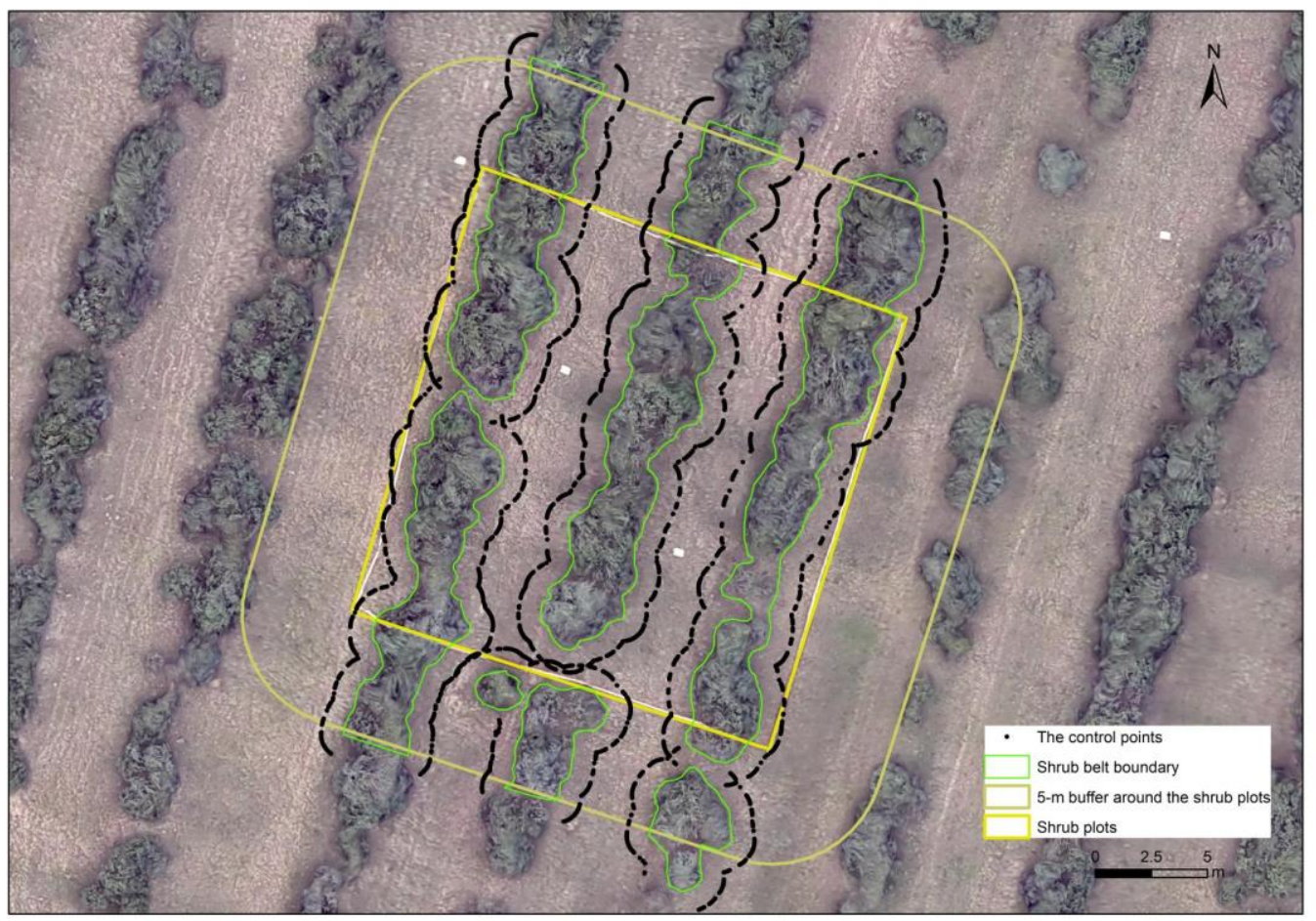

(b)

Figure 5. (a) 3D point cloud of the shrub belts and (b) the points for kriging interpolation to estimate the missing surface of the digital terrain model sheltered by the shrub canopy in the shrub plot. The green line is the shrub belt boundary. The dark dotted line shows the control points selected at the 1-m buffer outside the shrub boundary. The yellow dotted line is the spatial extent of the interpolation surface, forming a 5-m buffer around the shrub plots. The white points are the ground control points from RTK (Real - time kinematic). 


\subsection{Estimated Empirical Equation and Verification}

In general, the aboveground carbon stock will increase with the increase in the shrub belt volume. The volume and field-surveyed carbon stock of shrub belts in plots G1 and G2 were treated as training data. Based on the study by Williams [34], a simple linear model was used to link the aboveground carbon stock with the shrub belt volume, as follows:

$$
C_{\text {stock }}=b\left[V_{\text {shrub belt }}\right]+a( \pm S),
$$

where $a$ and $b$ are model coefficients; $\left[V_{\text {shrub belt }}\right]$ is the shrub belt volume; and $S$ is the standard error in fitting the model to the observations. This study considered nine shrub belts: six were set as training belts and three were set as validation belts. The accuracy of the obtained results, namely the $C_{\text {stock }}$ of three verification belts from the field survey and empirical equation, were determined using the coefficient of determination $\left(R^{2}\right)$ and the root mean square error (RMSE), which are calculated are as follows:

$$
\begin{gathered}
R^{2}=\frac{\sum_{i=1}^{n}\left(x_{i}-x\right)^{2}\left(y_{i}-y\right)^{2}}{\sum_{i=1}^{n}\left(x_{i}-x\right)^{2} \sum_{i=1}^{n}\left(y_{i}-y\right)^{2}} \\
\text { RMSE }=\sqrt{\frac{\sum_{i=1}^{n}\left(x_{i}-y_{i}\right)^{2}}{n}}
\end{gathered}
$$

where $x_{i}$ and $y_{i}$ are the estimated and measured values, respectively; $x$ and $y$ are the average estimated and measured values, respectively; and $n$ is the total number of existing values with respect to the compared parameters.

In order to avoid the model instability caused by small samples, leave-one-out cross-validation (LOOCV) was used to evaluate model performance. One set of data was used for testing (testing data), and the aboveground carbon stocks model was fit on the remaining data (training group). The fitted aboveground carbon stocks were then used to predict the testing data and repeated until the predictions for all data were generated. The accuracy and prediction ability of the model were assessed using the root-squared error of LOOCV (RMSE $\left.E_{L O O C V}\right)$, mean-squared error (MSE), and based $\mathrm{R}^{2}\left(R_{M S E}^{2}\right)$.

$$
\begin{gathered}
R M S E_{L O O C V}=\sqrt{\frac{1}{n} \sum_{i=1}^{n}\left(y_{i}-\hat{y}_{i}\right)^{2}} \\
M S E=\frac{1}{n} \sum_{i=1}^{n}\left(y_{i}-y\right)^{2} \\
R_{M S E}^{2}=\max \left(0,1-\frac{R M S E}{M S E}\right)
\end{gathered}
$$

where $n$ is the number of data; MSE denotes the mean-squared error of data; $y_{i}$ is the date of observation; $\hat{y_{i}}$ is the data of prediction; and $y$ is the mean of observation. The $R_{M S E}^{2}$ is the measure of fit to the 1:1 line.

\section{Results}

\subsection{Aboveground Carbon Stock of Surveyed Shrub Belts}

The crown and height of 209 shrubs were measured through field survey in three plots. The shrub number varied between 16 to 28 in different belts. The average crown and height ranged between 1.41-1.71 $\mathrm{m}$ and $1.58-1.95 \mathrm{~m}$, respectively. The biomass and aboveground carbon stock of $C$. intermedia in the nine belts were calculated according to Equations (1) and (2). The aboveground carbon stock varied between 174.34 and $294.49 \mathrm{~kg}$ (Table 1). 
Table 1. Plant number, average crown, average height, and aboveground carbon stock.

\begin{tabular}{cccccc}
\hline Plot & Belts & $\begin{array}{c}\text { Shrub } \\
\text { Number }\end{array}$ & $\begin{array}{c}\text { Average } \\
\text { Crown } \\
(\mathbf{m})\end{array}$ & $\begin{array}{c}\text { Average } \\
\text { Height } \\
(\mathbf{m})\end{array}$ & $\begin{array}{c}\text { Aboveground } \\
\text { Carbon Stock } \\
\left.\mathbf{( k g ~ C O} \mathbf{2 e}_{\mathbf{e}}\right)\end{array}$ \\
\hline G1 & Belt-1 & 16 & $1.92 \pm 0.74$ & $1.93 \pm 0.46$ & $203.23 \pm 4.46$ \\
& Belt-2 & 21 & $1.71 \pm 0.64$ & $1.81 \pm 0.59$ & $241.31 \pm 6.24$ \\
& Belt-3 & 25 & $1.70 \pm 0.55$ & $1.91 \pm 0.49$ & $294.49 \pm 5.30$ \\
G2 & Belt-4 & 26 & $1.49 \pm 0.33$ & $1.95 \pm 0.24$ & $270.88 \pm 2.44$ \\
& Belt-5 & 24 & $1.62 \pm 0.39$ & $1.81 \pm 0.36$ & $255.20 \pm 3.28$ \\
& Belt-6 & 25 & $1.49 \pm 0.46$ & $1.88 \pm 0.61$ & $260.28 \pm 4.37$ \\
G3 & Belt-7 & 28 & $1.41 \pm 0.41$ & $1.72 \pm 0.50$ & $256.57 \pm 3.92$ \\
& Belt-8 & 16 & $1.59 \pm 0.34$ & $1.82 \pm 0.34$ & $174.34 \pm 2.85$ \\
& Belt-9 & 28 & $1.41 \pm 0.28$ & $1.58 \pm 0.50$ & $239.22 \pm 2.46$ \\
\hline
\end{tabular}

\subsection{Plant Volume Accounting for Shrub Belts Detected by a UAV}

The kriging surface was interpolated by 5754 control points around the shrub belts, shown as the green surface in Figure 6. There were 897,064, 1,048,575, and 1,154,800 testing points selected from G1, G2, and G3, respectively, to test the fitting accuracy between the kriging surface and DTM. Figure 6 shows the scatter plots between the kriging surface and DSM, and the Pearson correlation between these two factors is shown in Table 2. The three Pearson correlation coefficients were no less than $0.99(P<0.01)$ with a large sample size, indicating that the kriging surface and DTM had good fitting accuracy.

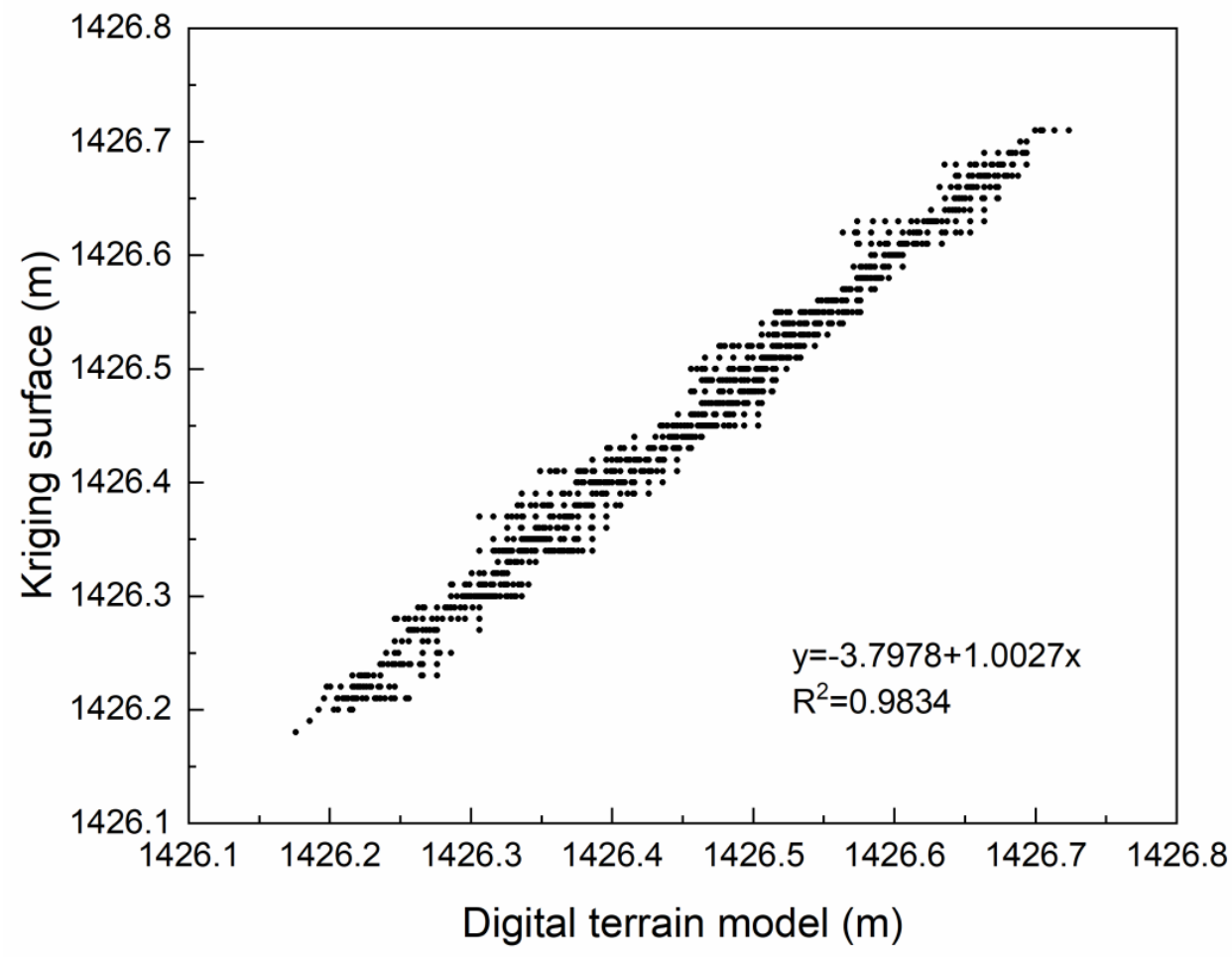

(a)

Figure 6. Cont. 


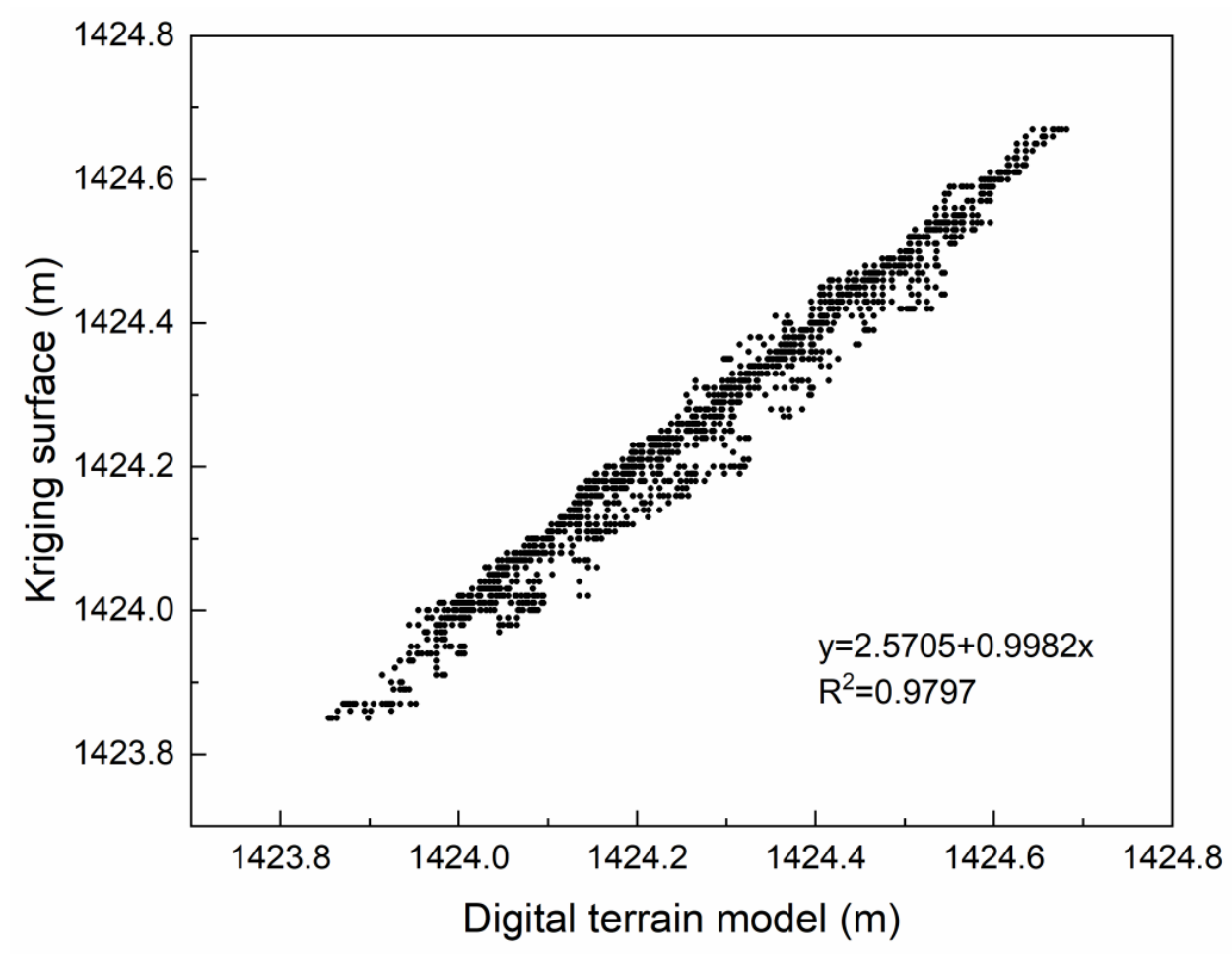

(b)

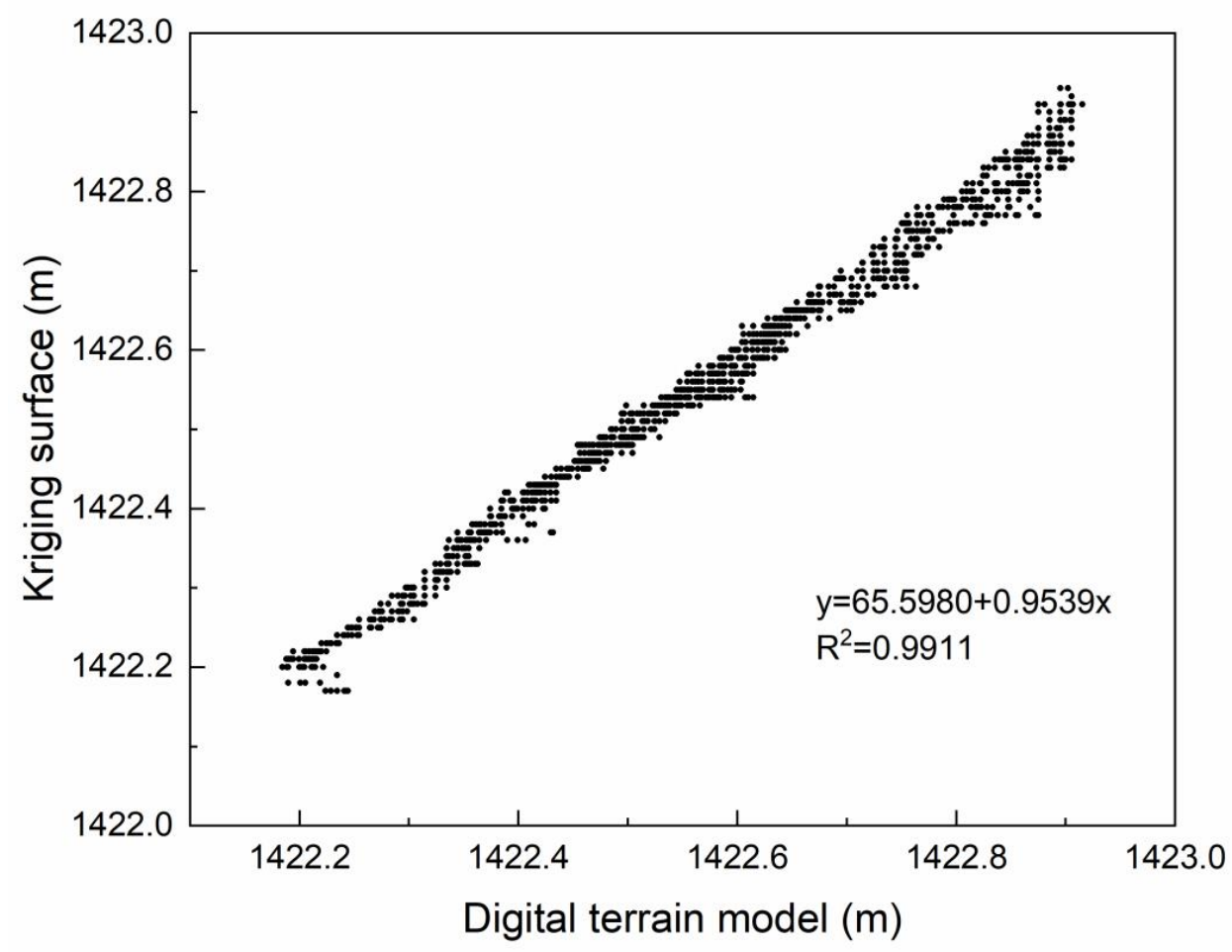

(c)

Figure 6. Scatter plots for (a) G1, (b) G2, and (c) G3. The $x$ coordinate represents the testing points of the DTM for surface height and the $y$ coordinate represents the testing points of the kriging surface. 
Table 2. Pearson correlation coefficient between the points of the DTM and kriging surface.

\begin{tabular}{cccc}
\hline Plots & Pearson Correlation Coefficient & P & N \\
\hline G1 & 0.99 & 0.00 & 897,064 \\
G2 & 0.99 & 0.00 & $1,048,575$ \\
G3 & 0.99 & 0.00 & $1,154,800$ \\
\hline
\end{tabular}

Figure 7a shows the CHM obtained by subtracting the kriging surface from the DSM, which clearly described the belt boundaries. According to Equation (4), the volume of the shrub belt is calculated as the total volume of all quadrangular prisms based on the bottom area (choose pixel size, $0.1 \mathrm{~m} \times 0.1 \mathrm{~m}$ ) multiplied by the height (canopy height), as shown in Table 3.

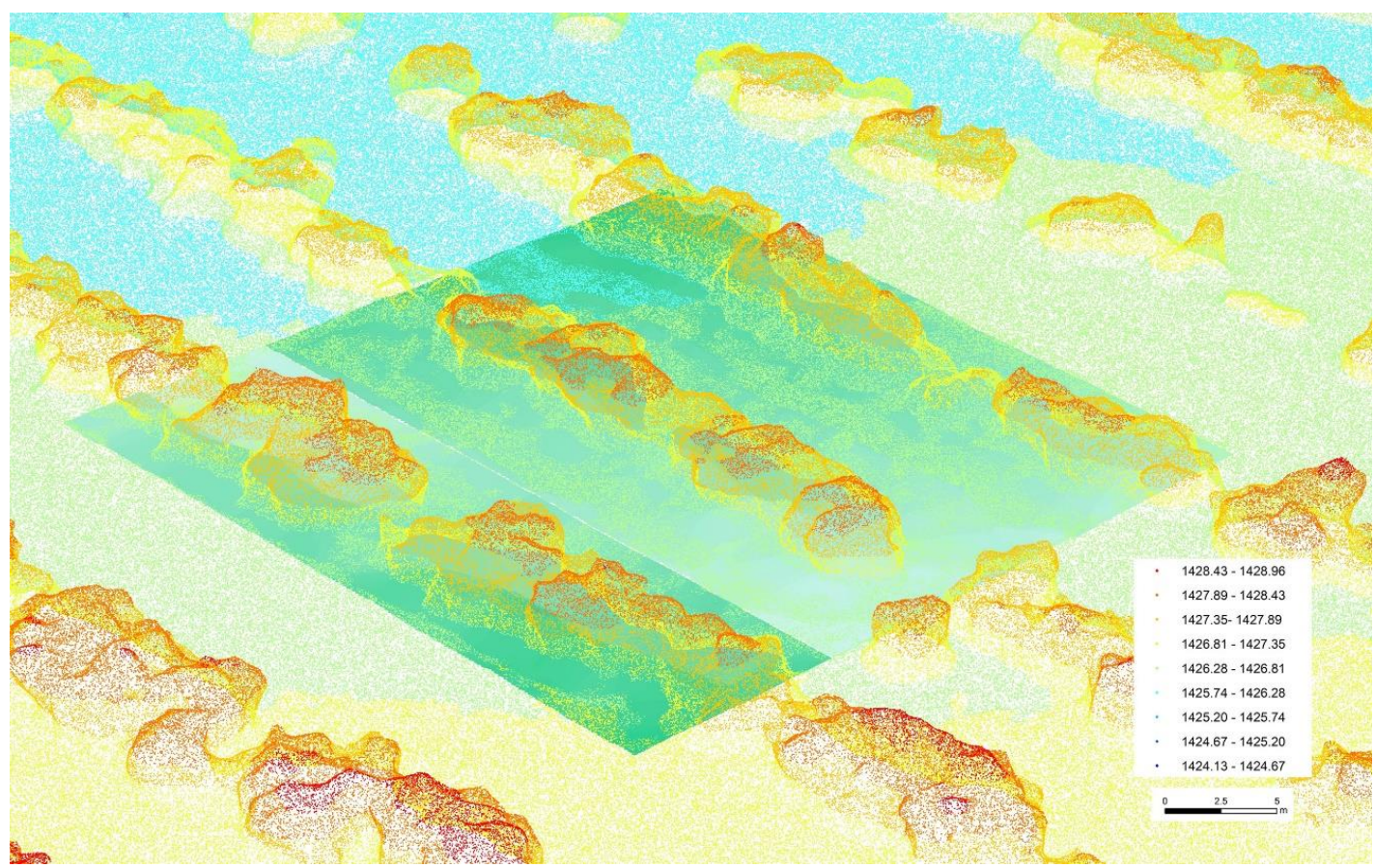

(a)

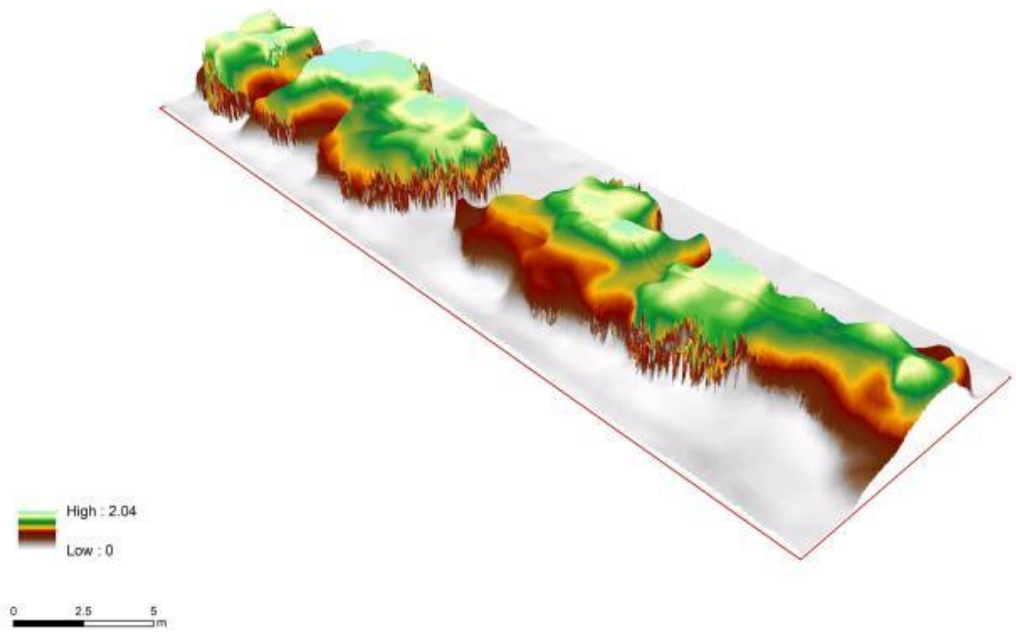

(b)

Figure 7. (a) Canopy height model obtained by subtracting the kriging surface from the DSM (m). (b) Volume of the shrub belt calculated using Equation (4). 
Table 3. Volume of the shrub belts detected by the UAV.

\begin{tabular}{|c|c|c|c|c|c|}
\hline Plot & & Belts & $\begin{array}{l}\text { Shrub Volume } \\
\qquad\left(\mathrm{m}^{3}\right)\end{array}$ & $\begin{array}{c}\text { Surveyed } \\
\text { Carbon Stock } \\
\left(\mathbf{k g ~ C O} \mathrm{CO}_{2 \mathrm{e}}\right)\end{array}$ & $\begin{array}{c}\text { Predicted } \\
\text { Carbon Stock } \\
\left(\mathrm{kg} \mathrm{CO}_{2 \mathrm{e}}\right)\end{array}$ \\
\hline \multirow{6}{*}{ Training data } & \multirow[t]{2}{*}{ G1 } & Belt-1 & $42.44 \pm 0.46$ & $203.23 \pm 4.46$ & - \\
\hline & & Belt-2 & $54.03 \pm 0.49$ & $241.31 \pm 6.24$ & - \\
\hline & \multirow{4}{*}{ G2 } & Belt-3 & $62.04 \pm 0.45$ & $294.49 \pm 5.30$ & - \\
\hline & & Belt-4 & $60.89 \pm 0.47$ & $270.88 \pm 2.44$ & - \\
\hline & & Belt-5 & $51.45 \pm 0.44$ & $255.20 \pm 3.28$ & - \\
\hline & & Belt-6 & $55.24 \pm 0.43$ & $260.28 \pm 4.37$ & - \\
\hline \multirow{3}{*}{ Validation data } & \multirow[t]{3}{*}{ G3 } & Belt-7 & $57.41 \pm 0.44$ & $256.57 \pm 3.92$ & 266.72 \\
\hline & & Belt- 8 & $36.78 \pm 0.38$ & $174.34 \pm 2.85$ & 182.56 \\
\hline & & Belt-9 & $43.36 \pm 0.33$ & $239.22 \pm 2.46$ & 209.39 \\
\hline
\end{tabular}

\subsection{Estimated Empirical Equation and Verification}

According to Figure 8a, the aboveground carbon stock will increase with the increase in the volume of the shrub belt. Based on our calculation (for detailed methods, please refer to [35], an empirical equation was established using data pairs of the aboveground carbon stock and shrub belt volume from six belts in plots G1 and G2 (Figure 8a). The $R^{2}$ value was $0.89(P<0.01 ; N=6)$. The aboveground carbon stock is estimated as follows:

$$
C_{\text {stock }}=4.0804 V_{\text {shrub belt }}+32.473, \quad\left(R^{2}=0.89, P<0.01\right)
$$

In other words, $89 \%$ of the change in the aboveground carbon stock could be explained by the changes in the shrub belt volume. Thus, our results support that the aboveground carbon stock of densely planted shrub belts is positively related to the shrub belt volume.

According to the newly established equation for estimating aboveground carbon stock (Equation (11)), the aboveground carbon stock of the shrub belts in G3 was estimated using the shrub belt volume obtained by the UAV. The results are shown in Figure $8 \mathrm{~b}$ with data fitting by using a linear model. Here, $R^{2}=0.74(P<0.05 ; N=3)$ and RMSE $=18.79 \mathrm{~kg} \mathrm{CO}_{2 \mathrm{e}}$. The LOOCV results for the aboveground carbon stock model performed well. The $R M S E_{L O O C V}$ was $17.26 \mathrm{~kg} \mathrm{CO}_{2 \mathrm{e}}$ and $R_{M S E}^{2}$ was 0.74 , indicating that the model performance was good for making aboveground carbon stock predictions (Table 4).

Table 4. Performance of the prediction model for aboveground carbon stock.

\begin{tabular}{ccccc}
\hline Prediction Model & $\begin{array}{c}\text { RMSE } \\
\left(\mathbf{k g ~ C O} \mathbf{2 e}_{\mathbf{e}}\right)\end{array}$ & $\mathbf{R}^{\mathbf{2}}$ & $\begin{array}{c}\mathrm{RMSE}_{\text {LOOCV }} \\
\left(\mathbf{k g ~ C O} \mathbf{C O}_{\mathbf{2}}\right)\end{array}$ & $\mathbf{R}_{\text {MSE }}^{2}$ \\
\hline $\begin{array}{c}\text { Aboveground } \\
\text { carbon stock }\end{array}$ & 18.79 & 0.74 & 17.26 & 0.74 \\
\hline
\end{tabular}




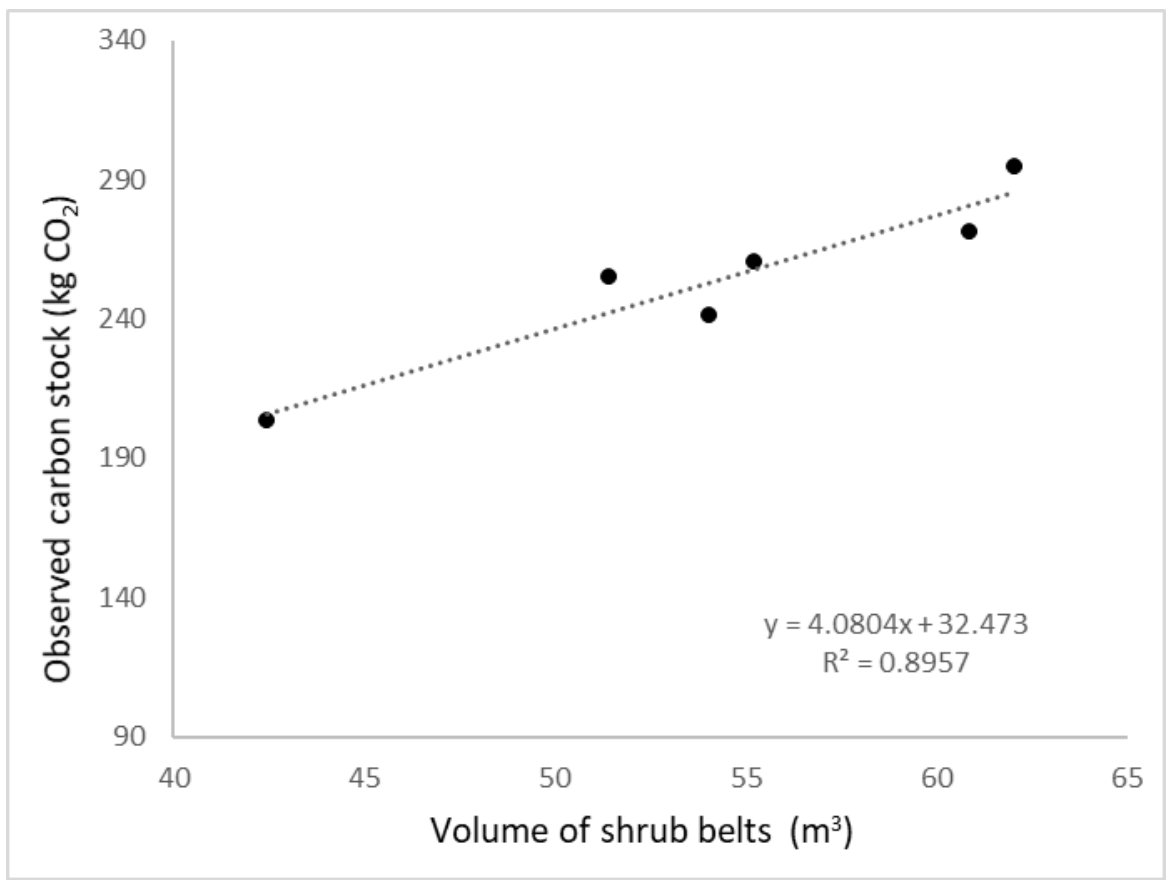

(a)

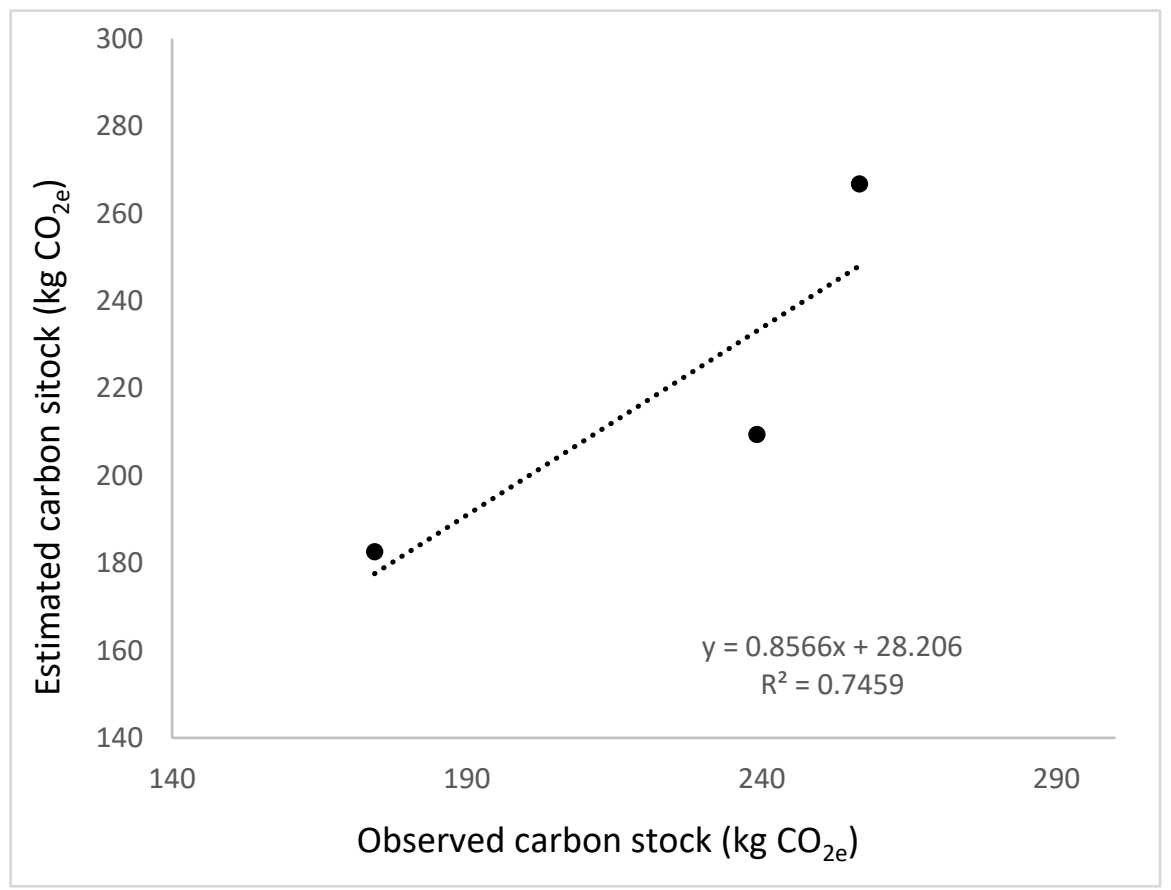

(b)

Figure 8. (a) Aboveground carbon stock vs. volume of six shrub belts in G1 and G2. (b) Carbon stock from field surveys vs. the estimated carbon stock through the newly established formulation of three belts in G3. The fitted curves are indicated by a black dotted line.

\section{Discussion}

To date, shrub owners have not found the carbon trade particularly attractive, and the CCER has not encouraged much new shrub. One important reason is that shrub projects of potential commercial value commonly require at least 10,000 ha, with no less than 200 sampling plots $(20 \mathrm{~m} \times 20 \mathrm{~m})$ [35], and every five years, the survey is repeated during the 20 -year project. Therefore, shrub owners 
experience significant challenge in completing the sampling work. In this study, a quick aboveground carbon stock estimation method was proposed for densely planted shrubs using 3D point cloud and an UAV. The core philosophy was to estimate the aboveground carbon stock, according to the volume of the densely planted shrubs. Therefore, the quick aboveground carbon-stock-estimation method using UAVs is a cheap and efficient method for introducing densely planted shrubs to the carbon market in China.

Accurate information about aboveground biomass are critical parameters for carbon stock accounting. Individual UAV-based tree detection for estimating aboveground biomass has been widely applied, where the height and crown are measured to derive the allometric equation [33]. Figure 2 shows that it is difficult to distinguish individual densely planted shrubs from the shrub belts, let alone measuring the height and crown of a single shrub. Therefore, in this study, a method was developed to estimate the aboveground carbon stock by measuring the shrub belt volume by using a UAV. According to the results shown in Figure 8a, a significant correlation exists between the aboveground carbon stock and shrub belt volume. Thus, it could be concluded that the shrub belt volume, which is easy to measure using UAVs, is suitable for estimating the aboveground carbon stock of densely planted shrubs.

In theory, the object height may be calculated from the UAV imagery through photogrammetry by subtracting the DTM from the DSM of the plant [36]. It is difficult to extract a DTM from a UAV-derived DSM because part of the terrain surface is sheltered by plant canopy [37]. It is also unclear if a UAV-derived DSM can estimate the elevation of an area with plants because plants have an irregular surface [38]. There are different methods of using UAV imagery to determine a suitable DTM for deriving vegetation height. Bendig et al. [38] and Possoch et al. [39] used the DTM of bare fields before plant sowing. This method is not suitable for carbon trade projects because C. intermedia was planted in 2010. Zarco-Tejada et al. [40] interpolated the ground points between trees to fill the gaps; this method is comparable to the method in our study (Figure 5a).

There are several sources of error for the proposed aboveground carbon-stock-estimation method. The maximum vegetation height is often not derived from UAV images because of the low density of the upper plant layer and wind disturbance. Conversely, the UAV measurements were biased toward lower plants than those determined in the field survey [37]. There was also uncertainty in the interpolation process. Intervals of approximately $2 \mathrm{~m}$ existed between the artificially planted shrub belts containing a sporadic growth of L. chinensis. As the growth area of L. chinensis was small and due to the low maximum height of this grass, its height in this study was negligible. The number of plots was relatively small, which limited the generality of the proposed estimation model. Although the prediction ability of the model was determined using LOOCV, the model was reliable when applied locally, but it lacked a generalization ability. Furthermore, in August 2018, the study area received abundant rainfall and luxuriant shrub growth. In case of drought years or seasons, the number of shrub leaves is small, and this may lead to large changes in volume estimation and have an important impact on the model parameters. Therefore, more plots in different locations and times should be developed in subsequent experiments, after which the model results could be more reliable.

In this study, the aboveground biomass and carbon stock was estimated through a field survey and UAV. However, actual carbon trading requires both the aboveground and underground carbon stock of shrubs. Based on our estimation model of the aboveground carbon stock, the root/shoot ratio could be introduced to estimate the underground carbon sink. Dang et al. [25] proposed that the root/shoot ratio was 1.17, as obtained through a whole root digging method. For carbon estimation of $C$. intermedia, whole carbon sink estimation is achievable. Moreover, the carbon sink calculation requires a series of UAV data to calculate the difference between carbon stocks in the baseline scenario and the scenario with a carbon-stock increase. 


\section{Conclusions}

In this study, the issue of the carbon accounting of densely planted shrubs was addressed through a field survey and by using a UAV. The statistical results showed that the aboveground carbon stock would increase with the increase in the shrub belt volume. Accordingly, a quick aboveground carbon-stock-estimation method using a UAV was established for densely planted shrubs. This proved to be a potential alternative to the time-consuming and expensive plot investigations conducted to estimate aboveground carbon stock, which is significant for shrub projects to take part in the carbon trading market in China.

Author Contributions: The research design, data analysis, and the paper writing were completed by X.Z.

Funding: This research was funded by the National Key R\&D Program of China (No. 2016YFC0500508 and No. 2018YFC1508805), and the National Natural Science Foundation of China (No. 31600351) and the Strategic Priority Research Program of Chinese Academy of Sciences (XDA20010302).

Conflicts of Interest: The authors declare no conflicts of interest.

\section{References}

1. Lewis, S.L.; Wheeler, C.E.; Mitchard, E.T.A.; Koch, A. Restoring natural forests is the best way to remove atmospheric carbon. Nature 2019, 568, 25-28. [CrossRef]

2. Gallagher, K.L.; Zhang, F.; Orvis, R.; Rissman, J.; Liu, Q. Assessing the policy gaps for achieving China's climate targets in the Paris Agreement. Nat. Commun. 2019, 3, 1-9.

3. International Carbon Action Partnership (ICAP). Emissions Trading Worldwide: Status Report 2018. Available online: https://icapcarbonaction.com/en/?option=com_attach\&task=download\&id=547Tang (accessed on 19 March 2019).

4. Tang, C.F.; Tu, Y.J.; Dai, L.M.; Tan, X.Y. The Present Situation and Suggestions for CCER Forestry Carbon Sink Project Development. J. Sichuan For. Sci. Technol. 2017, 38, 115-119.

5. Lewis, E. Intergovernmental Panel on Climate Change. Sustainaspeak 2018, 1, 153-154.

6. Zhang, D. China's forest expansion in the last three plus decades: Why and How? For. Policy Econ. 2019, 98, 75-81. [CrossRef]

7. Piao, S.; Mohammat, A.; Fang, J.; Cai, Q.; Feng, J. NDVI-based increase in growth of temperate grasslands and its responses to climate changes in China. Glob. Environ. Chang. 2006, 16, 340-348. [CrossRef]

8. Gong, C.; Bai, J.; Wang, J.; Zhou, Y.; Kang, T.; Wang, J.; Hu, C.; Guo, H.; Chen, P.; Xie, P.; et al. Carbon Storage Patterns of Caragana korshinskii in Areas of Reduced Environmental Moisture on the Loess Plateau, China. Sci. Rep. 2016, 6, 28883. [CrossRef]

9. Tao, Y.; Zhang, Y.M. Evaluation of vegetation biomass carbon storage in deserts of Central Asia. Arid Land Geogr. 2013, 8, 151-162.

10. Pooter, H.; Niklas, K.J.; Reich, P.B.; Oleksyn, J.; Poot, P.; Mommer, L. Biomass allocation toleaves, stems and roots: Meta-analyses of interspecific variation and environmental control. N. Phytol 2012, 193, 30-50. [CrossRef]

11. Lin, B.; Ge, J. Valued forest carbon sinks: How much emissions abatement costs could be reduced in China. J. Clean. Prod. 2019, 224, 455-464. [CrossRef]

12. Alexander, C.; Korstjens, A.H.; Hankinson, E.; Usher, G.; Harrison, N.; Nowak, M.G.; Abdullah, A.; Wich, S.A.; Hill, R.A. Locating emergent trees in a tropical rainforest using data from an Unmanned Aerial Vehicle (UAV). Int. J. Appl. Earth Obs. Geoinf. 2018, 72, 86-90. [CrossRef]

13. Puliti, S.; Ene, L.T.; Gobakken, T.; Næsset, E. Use of partial-coverage UAV data in sampling for large scale forest inventories. Remote Sens. Environ. 2017, 194, 115-126. [CrossRef]

14. Purnamasayangsukasih, P.R.; Norizah, K.; Ismail, A.A.M.; Shamsudin, I. A review of uses of satellite imagery in monitoring mangrove forests. IOP Conf. Ser.: Earth Environ. Sci. 2016, 37, 12034. [CrossRef]

15. Wallace, L.; Lucieer, A.; Malenovský, Z.; Turner, D.; Vopěnka, P. Assessment of Forest Structure Using Two UAV Techniques: A Comparison of Airborne Laser Scanning and Structure from Motion (SfM) Point Clouds. Forests 2016, 7, 62. [CrossRef] 
16. González-Jaramillo, V.; Fries, A.; Bendix, J. AGB Estimation in a Tropical Mountain Forest (TMF) by Means of RGB and Multispectral Images Using an Unmanned Aerial Vehicle (UAV). Remote Sens. 2019, 11, 1413. [CrossRef]

17. Li, Q.; Wang, Y.; Zhu, Y.; Li, H.; Jia, Z.; Liu, H. Effects of soil improvement of Caragana intermedia plantations in alpine sandy land on Tibet Plateau. Acta Ecol. Sin. 2014, 34, 123-128. [CrossRef]

18. Guo, H.Y.; Gao, Y.B.; Ma, C.C.; Ren, A.Z.; Wu, J.B.; Wang, Y.H. Genetic diversity and genetic relationship of Caragana microphylla, Caragana davazamcii and Caragana korshinskii in Inner Mongolia Plateau. Acta Ecol. Sin. 2008, 28, 3729-3736.

19. Rao, M.P.; Davi, N.K.; D’Arrigo, R.D.; Skees, J.; Nachin, B.; Leland, C.; Lyon, B.; Wang, S.-Y.; Byambasuren, O. Dzuds, droughts, and livestock mortality in Mongolia. Environ. Res. Lett. 2015, 10, 74012. [CrossRef]

20. Zhang, H.; Fan, J.; Cao, W.; Harris, W.; Li, Y.; Chi, W.; Wang, S. Response of wind erosion dynamics to climate change and human activity in Inner Mongolia, China during 1990 to 2015. Sci. Total Environ. 2018, 639, 1038-1050. [CrossRef]

21. Shang, C.W.; Wu, T.; Huang, G.L.; Wu, J.G. Week sustainability is not sustainable: Socioeconomic and environmental assessment of Inner Mongolia for the past three decades. Resour. Conserv. Recycl. 2019, 141, 243-252. [CrossRef]

22. Zhou, W.; Yang, H.; Zhou, L.; Chen, Y.; Huang, L.; Ju, W. Dynamics of grassland carbon sequestration and its coupling relation with hydrothermal factor of Inner Mongolia. Ecol. Indic. 2018, 95, 1-11. [CrossRef]

23. John, R.; Chen, J.; Giannico, V.; Park, H.; Xiao, J.; Shirkey, G.; Ouyang, Z.; Shao, C.; Lafortezza, R.; Qi, J. Grassland canopy cover and aboveground biomass in Mongolia and Inner Mongolia: Spatiotemporal estimates and controlling factors. Remote Sens. Environ. 2018, 213, 34-48. [CrossRef]

24. Niu, C.Y.; Alamusa, D.; Zong, Q.; Luo, Y.M.; Oshid, T.; Sun, G.F.; Liu, Q. Allocation patterns of above- and below-ground biomass of Caragana microphylla in Horqin Sandy land, North China. Chin. J. Ecol. 2013, 32, 1980-1986.

25. Dang, X.H.; Gao, Y.; Yu, Y.; Meng, Z.J.; Liu, Y.; Wang, S.; Wu, H.; Ding, Y.L.; Liu, B. The biomass estimation models for eight desert shrub species in northern edge of the Hobq Desert. J. Arid Land Resour. Environ. 2016, 30, 168-174.

26. Wang, J.; Tang, J.; Guo, Y.F.; Gao, Y.H.; Yao, Y.F. Aboveground biomass estimation model of two shrubs to Aohan banner northern wind-sandy area in Inner Mongolia. Agric. Eng. 2015, 5, 44-47.

27. Wei, W.; Zhao, J.; Qing, H.; Zeng, J. Study on the measurement method of carbon sink in Kubuqi Desert shrub—taking Caragana korshinskii and salix as example. J. Chifeng Univ. 2016, 32, 118-121.

28. Dilek, K.; Serdar, S.; Nagihan, A.; Bekir, T.S. Automatic citrus tree extraction from UAV images and digital surface models using circular hough transform. Comput. Electron. Agric. 2018, 150, 289-301.

29. Frey, J.; Kovach, K.; Stemmler, S.; Koch, B. UAV ptotogrammetry of forests as a vulnerable process. A sensitivity analysis for a structure from motion RGB-image pipeline. Remote Sens. 2018, 10, 912.

30. Agisoft. Agisoft Photoscan UserManual, 2014. Agisoft LLC: St. Petersburg, Russia. Available online: http://www.agisoft.com/pdf/photoscan-pro_1_1_en.pdf (accessed on 15 June 2018).

31. Torres-Sánchez, J.; De Castro, A.I.; Peña, J.M.; Jiménez-Brenes, F.M.; Arquero, O.; Lovera, M.; López-Granados, F. Mapping the 3D structure of almond trees using UAV acquired photogrammetric point clouds and object-based image analysis. Biosyst. Eng. 2018, 176, 172-184. [CrossRef]

32. González-Jaramillo, V.; Fries, A.; Zeilinger, J.; Homeier, J.; Paladines-Benitez, J.; Bendix, J. Estimation of Above Ground Biomass in a Tropical Mountain Forest in Southern Ecuador Using Airborne LiDAR Data. Remote Sens. 2018, 10, 660. [CrossRef]

33. Baltsavias, E.P. A comparison between photogrammetry and laser scanning. ISPRS J. Photogramm. Remote Sens. 1999, 54, 83-94. [CrossRef]

34. Williams, F. Reasoning with Statistics: How to Read Quantitative Research; Harcourt Brace Jovanovich College Publishers: Fort Worth, TX, USA, 1992; pp. 12-16.

35. UNFCCC. Calculation of the Number of Sample Plots for Measurements within A/R CDM Project Activities (Version 02.1.0). Available online: https://cdm.unfccc.int/methodologies/ARmethodologies/tools/ar-am-tool03-v2.1.0.pdf (accessed on 09 October 2019).

36. Weidner, U.; Förstner, W. Towards automatic building extraction from high-resolution digital elevation models. ISPRS J. Photogramm. Remote Sens. 1995, 50, 38-49. [CrossRef] 
37. Wimala, V.I.; Menno, S.; Elisabeth, A.; Hans, M. Monitoring height and greenness of non-woody floodplain vegetation with UAV time series. ISPRS J. Photogram. Remote Sens. 2018, 141, 112-123.

38. Bendig, J.; Yu, K.; Aasen, H.; Bolten, A.; Bennertz, S.; Broscheit, J.; Gnyp, M.L.; Bareth, G. Combining UAV-based plant height from crop surface models, visible, and near infrared vegetation indices for biomass monitoring in barley. Int. J. Appl. Earth Obs. Geoinf. 2015, 39, 79-87. [CrossRef]

39. Possoch, M.; Bieker, S.; Hoffmeister, D.; Bolten, A.; Schellberg, J.; Bareth, G. Multi-temporal crop surface models combined with the RGB vegetation index from UAV-based images for forage monitoring in grassland. ISPRS-Int. Arch. Photogramm. Remote Sens. Spat. Inf. Sci. 2016, XLI-B1, 991-998.

40. Zarco-Tejada, P.J.; Diaz-Varela, R.; Angileri, V.; Loudjani, P. Tree height quantification using very high resolution imagery acquired from an unmanned aerial vehicle (UAV) and automatic 3D photo-reconstruction methods. Eur. J. Agron. 2014, 55, 89-99. [CrossRef]

(C) 2019 by the author. Licensee MDPI, Basel, Switzerland. This article is an open access article distributed under the terms and conditions of the Creative Commons Attribution (CC BY) license (http://creativecommons.org/licenses/by/4.0/). 